\title{
Underlying liver disease and advanced stage liver cancer are associated with elevated neutrophil-lymphocyte ratio
}

\author{
Linda Wong', Kliment Bozhilov', Brenda Hernandez², Sandi Kwee ${ }^{3}$, Owen Chan $^{2}$, Luke Ellis', and Loic LeMarchand ${ }^{2}$ \\ 'Department of Surgery, University of Hawaii, Honolulu, HI; ${ }^{2}$ Cancer Center, University of Hawaii, Honolulu, HI; ${ }^{3}$ Positron Emission \\ Tomography Research Center, The Queens Medical Center, Honolulu, HI, USA
}

Background/Aims: Inflammation-based scores, such as the neutrophil-to-lymphocyte ratio (NLR), have been associated with prognosis in hepatocellular carcinoma (HCC); but variable cut-off values and potential lack of specificity have limited the utility of NLR. This study evaluates NLR in a large cohort of HCC patients.

Methods: We retrospectively reviewed 789 HCC cases (1993-2017) for demographics, tumor characteristics, treatment, and survival. NLR was stratified into NLR $\geq 1.5$ and NLR $\geq 3$ and analyzed for correlation with American Joint Committee on Cancer (AJCC) and Barcelona Clinic Liver Cancer (BCLC) stages. In 235 patients who underwent liver resection, survival and recurrence were evaluated by NLR.

Results: In 789 HCC cases, mean NLR was increased with advanced AJCC and BCLC stages. Hepatitis C patients were less likely to have NLR $\geq 1.5$ and $\geq 3$. Non-alcoholic steatohepatitis patients were more likely to have NLR $\geq 3$. Patients with tumor size $>5 \mathrm{~cm}$, rupture, or macrovascular invasion were more likely to have NLR $\geq 3$. In patients treated with resection, $\mathrm{NLR} \geq 3$ predicted early recurrence (odds ratio $[\mathrm{OR}] 4.14, P<0.01$ ) and overall recurrence (OR $4.05, P<0.01)$. Mean NLR was 4.30 in those with recurrence and 2.75 in those without recurrence. Patients with NLR $\geq 3$ showed significantly worse survival compared to those with NLR $<3$ ( $P<0.01$ by log-rank test).

Conclusions: Elevated NLR is associated with advanced cancer stage and aggressive tumor characteristics, such as large size, rupture, and invasion. NLR $\geq 3$ was associated with early and overall recurrence after resection but varied with etiology. NLR may be a useful biomarker in predicting recurrence for HCC patients undergoing curative resection, but further studies are required to elucidate the effect of disease etiology. (Clin Mol Hepatol 2019;25:305-316)

Keywords: Hepatocellular carcinoma; Liver cancer

\footnotetext{
Study Highlights

Using a prospectively collected database we explored the value of neutrophil-lymphocyte ratio (NLR) in hepatocellular carcinoma patients undergoing resection. Previous studies have shown that NLR can be a prognostic factor for recurrence and survival. However, our study demonstrates that Asian race, hepatitis C, non-alcoholic steatohepatitis, and diabetes affect NLR, despite NLR being a marker for disease severity, with increased values in patients with large tumors, vascular invasion, and tumor rupture. These intervening factors may render NLR difficult to interpret, and cutoff values may be difficult to establish; future studies need to address this.
}

\footnotetext{
Abbreviations:

AFP, alpha-fetoprotein; AJCC, American Joint Committee on Cancer; AST, aspartate aminotransferase; BCLC, Barcelona Clinic Liver Cancer; BMI, body mass index; CT, computed tomography; HBV, hepatitis B virus; $H C C$, hepatocellular carcinoma; $\mathrm{HCV}$, hepatitis $\mathrm{C}$ virus; IL, interleukin; MRI, magnetic resonance imaging; NASH, non-alcoholic steatohepatitis; NLR, neutrophil-lymphocyte ratio; $\mathrm{OR}$, odds ratio; ROC, receiver operating curves; SD, standard deviation
}

\section{Corresponding author : Linda Wong}

Department of Surgery, University of Hawaii, 550 S Beretania St \#403, Honolulu, HI 96813, USA

Tel: +1-808-523-5033, Fax: +1-808-528-4940

E-mail: Hepatoma@aol.com

https://orcid.org/0000-0003-3143-5384 


\section{INTRODUCTION}

Liver cancer is the fifth most common cancer in men and ninth in women but is the second most common cause of cancer death worldwide.' Hepatocellular carcinoma (HCC) comprises $80 \%$ of primary liver cancers and is usually caused by the chronic inflammation induced by hepatitis B virus (HBV) and hepatitis C virus $(\mathrm{HCV}){ }^{2,3}$ However, due to the increased incidence of metabolic syndrome and nonalcoholic fatty liver disease, HCC is now the fastest rising cause of cancer death in the United States. ${ }^{4,5}$

Management of this deadly cancer is complicated by tumor characteristics along with underlying liver function. ${ }^{6,7}$ Curative therapies include hepatic resection, local ablation and liver transplantation, but recurrence rates are as high as 70 and $20 \%$, respectively. ${ }^{8-13}$ Although current staging systems identify important prognostic factors for survival and management, they are primarily based on radiographic findings and may not provide enough information on tumor biology, which may ultimately drive tumor recurrence.

Tissue and serum biomarkers have been less explored in HCC staging. Alpha-fetoprotein (AFP) is the only biomarker that has had some evidence of being prognostic; but it is not useful for staging, due to limited sensitivity and specificity. ${ }^{14,15}$ Recently, there has been growing interest in inflammatory biomarkers since inflammation is a critical component of tumorigenesis in $\mathrm{HCC}^{16}$ Moreover, the inflammatory tumor microenvironment has been implicated in tumor progression with elevated levels of infiltrating T-regulatory cells offering worse prognosis while elevated levels of lymphocytes and cytotoxic T cells control tumor progression. 17-19 A persistent inflammatory milieu mediated by non-specific neutrophilia coupled with a relative lymphopenia, which could prevent a host immune-mediated antitumor response, may promote HCC tumor progression. ${ }^{20}$

The neutrophil-lymphocyte ratio (NLR) is the most widely studied inflammatory marker for various diseases, including HCC, and may offer prognostic value. ${ }^{21}$ Most studies demonstrate that an elevated NLR value confers worse outcomes in HCC after hepatic resection. ${ }^{21-31}$ However, cut-off values for NLR are variable across studies; and few studies have examined underlying etiology, rendering the use of NLR difficult to generalize. In this study we characterize a large cohort of HCC patients in terms of risk factors and tumor characteristics, as it relates to NLR. Secondly we analyze patients who underwent liver resection to determine factors, including NLR, that may affect survival and recurrence.

\section{MATERIALS AND METHODS}

\section{Patients}

This is a retrospective cohort study of 1,262 HCC cases referred over a 25-year period (1993-2017) to a group of physicians who are associated with Hawaii's only liver transplant center and referral center for liver disease/surgery for the American territories of the Pacific Basin (including Samoa, Guam, Saipan, and the Marshall Islands). Patients also included foreign nationals from Asian countries who sought medical care in the United States. These clinic and transplant centers were initially affiliated with St. Francis Medical Center (later renamed Hawaii Medical Center-East) and Queen's Medical Center in Honolulu, Hawaii after 2012. This center sees approximately $60-70 \%$ of the HCC cases in Hawaii. This study included all patients who were referred to these centers during the study period. This study was approved by the Institutional Review Board of The University of Hawaii at Manoa. This was a retrospective study using deidentified data that were determined to be exempt from requiring patients' consent and were in compliance with ethical regulations.

\section{Diagnosis of HCC}

HCC was diagnosed histologically by percutaneous biopsy or at surgery. In the first decade and consistent with the previous United Network for Organ Sharing policy regarding transplant for HCC, patients without histologic confirmation were included if they had a history of chronic liver disease, a mass at least $2 \mathrm{~cm}$ seen on two imaging studies (ultrasound, computed tomography [CT] scan or magnetic resonance imaging [MRI]), and one of the following: (1) vascular blush evident on CT scan or MRI, (2) AFP $>200 \mathrm{ng} / \mathrm{mL}$ or (3) arteriogram confirming the tumor. More recently, the diagnosis of HCC was made with imaging alone if a contrast-enhanced study (dynamic CT or MRI) showed typical arterial enhancement with "washout" in the venous phase, as described by the American Association for the Study of Liver Disease guidelines. ${ }^{6}$

\section{Data collected}

Information on demographics, medical history, laboratory data, tumor characteristics, treatment, and survival was collected from clinical records. Demographic data included age, sex, birthplace, and the patient's self-reported ethnicity. Ethnicity was then cate- 
gorized as "White", "Asian" (East Asians, including Filipinos), "Pacific Islander", "Mixed", or "Other." Medical history included diabetes mellitus, hyperlipidemia, smoking, and risk factors for HCC including viral hepatitis, alcohol abuse (defined as greater than two alcoholic beverages daily for at least ten years), and other chronic liver diseases. Measured height and weight were used to determine body mass index (BMI). Obesity was defined as $\mathrm{BMI} \geq 30$.

The collected laboratory data included bilirubin, albumin, prothrombin time with international normalized ratio, creatinine, alanine aminotransferase, aspartate aminotransferase (AST), platelet count, neutrophil count, lymphocyte count, and AFP. HBV and HCV serologies were obtained if this information was not available from pre-existing records. Laboratory data that was used for the study had been obtained within 2 weeks of an initial visit or at the time of the visit. NLR and Model for End-stage Liver Disease score were calculated. The size, number, and location of the tumor(s) were used to determine the Tumor Node Metastases stage according to the American Joint Committee on Cancer (AJCC) staging system. Tumors were stratified to largest tumor diameter $\geq 5 \mathrm{~cm}$ or $<5 \mathrm{~cm}$. We also noted whether the tumor had macrovascular invasion (based on imaging), rupture at presentation, and/or underlying cirrhosis. Normal AFP was defined as less than $20 \mathrm{ng} / \mathrm{dL}$.

Although our Liver Center recommends HCC surveillance in cirrhotics with AFP and liver ultrasound every 6 months, there was no uniform screening protocol used in the cohort. Referring physicians used a combination of AFP and/or imaging (ultrasound, CT scan or MRI) at variable intervals. HCC was deemed to be found on "screening" if the patient had a previous imaging study from three to twelve months prior to the current study. HCC not found on screening was either found with symptoms (pain, abdominal mass, weight loss, jaundice) or incidentally with imaging done for unrelated reasons.

\section{Treatments}

Treatments included liver resection, transplantation, ablative therapies (including radiofrequency ablation, cryosurgery, transarterial chemoembolization, and percutaneous ethanol injection) and systemic therapies. Liver resection was considered in Child A patients and early Child B patients (Child-Turcotte-Pugh score of 7, without any evidence of ascites or encephalopathy). Liver transplants were considered in patients who were unresectable but met Milan criteria (single tumor less than $5 \mathrm{~cm}$ or 2 to 3 tumors, each less than $3 \mathrm{~cm}$ ). Liver transplant was also considered in patients who underwent resection but had a recurrence more than 6 months after surgery, provided the recurrent tumor met Milan criteria. Since 2007, liver transplant was considered in single tumors $<6.5 \mathrm{~cm}$ that were down-staged to meet Milan criteria. All liver resections and transplants were performed by a single surgical group practice. The majority of patients on the transplant list underwent locoregional therapy while waiting for a donor.

\section{Data categories - entire cohort and resected patients}

Of the entire cohort, 789 patients had information to calculate NLR. This cohort was used to calculate mean NLR by AJCC and Barcelona Clinic Liver Cancer (BCLC) stages. We also divided NLR into several categories including NLR 1.5 or higher (NLR $\geq 1.5$ ) versus less than 1.5 and NLR 3.0 or higher (NLR $\geq 3$ ) versus NLR less than 3.0. We also determined predictors of NLR $\geq 1.5$ and NLR $\geq 3$ by calculating odds ratio (OR) with $95 \%$ confidence intervals on multiple clinical and tumor factors. Univariate and multivariate analysis were used to determine significant predictors of NLR $\geq 1.5$ and NLR $\geq 3$

We then focused this study on 235 patients who received a liver resection as an initial, curative therapy. These 235 patients were selected from the entire cohort of 1,262 patients. NLR was available in 166 of these patients. We included those patients with ruptured HCC who had initial transarterial embolization to control bleeding and then subsequent elective liver resection as definitive treatment. We also included those patients who had pre-operative portal vein embolization because of large HCC and inadequate future remnant volume, as measured by a radiologist and determined by the surgeon based on underlying liver function. We excluded four patients who underwent initial liver resection and subsequent salvage liver transplantation due to recurrence of HCC, as this would affect long-term disease-free survival and may not reflect the prognosis based on initial NLR.

Patients were followed long-term with contrast enhanced imaging every 3 months after surgery or loco-regional therapies for the first year and then every 4-6 months. After the first year or if patients had issues with intravenous contrast, ultrasound was used for follow up. Early recurrences were defined as recurrences within 1 year. Deaths were confirmed using the Social Security Death Index and local newspaper obituaries. Twelve patients (1.0\%) were lost to follow up. One patient had a liver resection and one had a liver transplant and was known to survive at least 5 years without recurrence before being lost to follow up. The 
others were patients who had non-curative or no therapy.

\section{Statistical analysis}

All analyses were performed using Excel and Statistical Package for Social Services (SPSS) statistical software ver. 23.0 (IBM Corp., Armonk, NY, USA). Categorical variables were analyzed using analysis of variance and chi-square analysis. OR with $95 \%$ confidence intervals were calculated using univariate and multivariate logistic regression. Predictors of recurrence were evaluated by unconditional logistic regression modeling recurrence/no recurrence. Variables significant at $P=0.10$ in univariate analyses were included in the multivariate models along with age and sex. Significant variables to $P=0.10$ were used to create a multivariate model. Variables significant at $P<0.05$ were considered significant in the multivariate model. Generalized linear models were used to compare NLR by AJCC and BCLC stage. Overall survival was evaluated using Kaplan-Meier and Cox regression analyses. Variables significant on univariate analysis $(P<0.05)$ were included in multivariate models.

\section{RESULTS}

\section{Baseline characteristics of the patients}

This cohort of 789 patients with NLR had baseline characteristics as shown in Table 1. The mean tumor size of the largest tumor was $5.5 \mathrm{~cm}$ (standard deviation [SD] $4.2 \mathrm{~cm}$ ), and $39.2 \%$ of tumors were $\geq 5 \mathrm{~cm}$. Tumor rupture was noted in $2.4 \%$, and macrovascular invasion noted in $8.5 \%$. In this cohort, 166 patients underwent liver resection and 12 patients underwent orthotopic liver transplant as the initial therapy. Of the remaining patients, 218 underwent locoregional therapy with transarterial chemoembolization or Yttrium90 radioembolization and 182 patients underwent radiofrequency or microwave ablation as their initial therapy. Twenty-four patients were not amenable to surgical or locoregional therapy and were given sorafenib. The remaining patients had a noncurative therapy, supportive care or no therapy.

\section{Factors associated with NLR in the entire cohort}

In the 789 patients with available information to calculate NLR, $80.4 \%$ of patients had NLR $\geq 1.5$. Univariate analysis showed that

Table 1. Baseline characteristics of the entire cohort and patients who underwent liver resection

\begin{tabular}{|c|c|c|}
\hline & Entire cohort $(n=789)$ & Liver resection $(n=235)$ \\
\hline Mean age (SD) & 64.2 years (11.0) & 62.8 years $(11.0)$ \\
\hline Female & $198(35.1)$ & $69(29.4)$ \\
\hline Asian race & $440(55.8)$ & $167(71.1)$ \\
\hline Hepatitis B+ & $168(21.3)$ & $70(29.8)$ \\
\hline Hepatitis C+ & $337(42.7)$ & $72(30.6)$ \\
\hline Alcohol abuse & $342(43.3)$ & 69 (29.4) \\
\hline $\mathrm{NASH}$ & $138(17.5)$ & $52(22.1)$ \\
\hline $\mathrm{BMI} \geq 30 \mathrm{~kg} / \mathrm{m}^{2}$ & $176(22.3)$ & $36(15.3)$ \\
\hline $\mathrm{BMI} \geq 35 \mathrm{~kg} / \mathrm{m}^{2}$ & $75(9.5)$ & $11(4.7)$ \\
\hline Smoking & $516(65.4)$ & $130(55.3)$ \\
\hline Diabetes mellitus & $278(35.2)$ & $69(29.4)$ \\
\hline Hyperlipidemia & $226(28.6)$ & $69(29.4)$ \\
\hline Hypertension & $472(59.8)$ & $134(57.0)$ \\
\hline Normal AFP & $345(43.7)$ & $112(47.7)$ \\
\hline Tumor size $\geq 5 \mathrm{~cm}$ & $309(39.2)$ & $117(49.8)$ \\
\hline HCC rupture & $19(2.4)$ & $24(10.2)$ \\
\hline Macrovascular invasion & $67(8.5)$ & $7(3.0)$ \\
\hline
\end{tabular}

Values are presented as $n(\%)$ unless otherwise indicated.

SD, standard deviation; NASH, non-alcoholic steatohepatitis; BMI, body mass index; AFP, alpha-fetoprotein; HCC, hepatocellular carcinoma. 
patients with diabetes and largest tumors size $5 \mathrm{~cm}$ or larger were more likely to have NLR $\geq 1.5$. Asians and HCV positivity were less likely to have NLR $\geq 1.5$ (Table 2). On multivariate analysis, Asian races, HCV positivity, diabetes and size $\geq 5 \mathrm{~cm}$ remained significantly associated with NRL $\geq 1.5$.

NLR $\geq 3$ was noted in $35.9 \%$ of all patients. Asian race and HCV positivity were less likely to be NLR $\geq 3$, while the presence of non-alcoholic steatohepatitis (NASH), tumor size $\geq 5 \mathrm{~cm}$, HCC rupture, and macrovascular invasion were significantly associated with NLR $\geq 3$. On multivariate analysis, HCV was no longer significantly associated. NASH, tumor size $\geq 5 \mathrm{~cm}, \mathrm{HCC}$ rupture, and macrovascular invasion were associated with NLR $\geq 3$ (Table 3).

Mean NLR was lower in patients with HCV compared to those who were HCV negative (2.89 vs. $3.63, P<0.01)$. Mean NLR was also higher in those patients with NASH compared to those without NASH (4.30 vs. 3.10, $P<0.01$ ), but diabetes did not affect mean NLR. Differences in mean NLR were also noted in tumor size $\geq 5 \mathrm{~cm}$ ( 3.96 vs. $2.89, P<0.01)$, HCC rupture (6.89 vs. 3.22 , $P<0.01$ ), and macrovascular invasion (4.14 vs. $3.23, P=0.03$ ) compared to those without these characteristics. The receiver operating curves (ROC) were as follows: tumor size $\geq 5 \mathrm{~cm}$ ( $R O C=0.666)$, tumor rupture $(R O C=0.809)$, and macrovascular invasion
(ROC $=0.631)$. There were also trends associated with increasing NLR by higher AJCC stage $(P=0.01)$ and BCLC stage $(P=0.16)$ as shown in Table 4.

\section{Patients treated with resection}

In this cohort, 235 patients underwent liver resection for HCC. This included 12 patients who underwent hepatic arterial embolization and three patients who underwent portal vein embolization prior to liver resection. Arterial embolization was done for tumor rupture on presentation in 11 patients and impending rupture/large size in one patient. Portal vein embolization was performed to hypertrophy the uninvolved liver to facilitate liver resection. Characteristics of this cohort are detailed in Table 1. Mean tumor size was $6.4 \mathrm{~cm}(\mathrm{SD} 4.45 \mathrm{~cm}$ ) with $49.8 \%$ having tumors $5 \mathrm{~cm}$ or larger. Single tumor was noted in $84.3 \%$ and macrovascular invasion was noted in $3 \%$.

\section{Predictors of recurrence}

In the 235 patients who underwent liver resection, 96 patients (40.9\%) had recurrence with mean follow-up time of 1,543 days

Table 2. Predictors of neutrophil-lymphocyte ratio $\geq 1.5$ in the entire cohort $(n=789)$

\begin{tabular}{|c|c|c|c|c|}
\hline & \multicolumn{2}{|c|}{ Univariate model } & \multicolumn{2}{|c|}{ Multivariate model } \\
\hline & OR $(95 \% \mathrm{Cl})$ & $P$-value & OR (95\% CI) & $P$-value \\
\hline Age $\geq 65$ years & $1.14(0.73-1.78)$ & 0.56 & $1.12(0.75-1.67)$ & 0.58 \\
\hline Female & $0.80(0.49-1.27)$ & 0.34 & $1.24(0.81-1.89)$ & 0.31 \\
\hline Asian (yes vs. no) & $0.38(0.21-0.67)$ & $<0.01$ & $0.61(0.40-0.92)$ & 0.02 \\
\hline Hepatitis B + & $1.42(0.71-2.85)$ & 0.32 & & \\
\hline Hepatitis C + & $0.41(0.27-0.60)$ & 0.02 & $0.43(0.28-0.65)$ & $<0.01$ \\
\hline Alcohol abuse & $1.01(0.63-1.61)$ & 0.98 & & \\
\hline NASH & $1.42(0.61-3.29)$ & 0.42 & & \\
\hline $\mathrm{BMI} \geq 30 \mathrm{~kg} / \mathrm{m}^{2}$ & $0.99(0.54-1.81)$ & 0.96 & & \\
\hline $\mathrm{BMI} \geq 35 \mathrm{~kg} / \mathrm{m}^{2}$ & $1.01(0.44-2.36)$ & 0.97 & & \\
\hline Smoking (yes or no) & $1.03(0.65-2.36)$ & 0.91 & & \\
\hline Diabetes & $1.72(1.07-2.76)$ & 0.02 & $1.65(1.08-2.50)$ & 0.02 \\
\hline Hyperlipidemia & $1.05(0.63-1.76)$ & 0.85 & & \\
\hline Hypertension & $0.83(0.54-1.27)$ & 0.38 & & \\
\hline Normal AFP & $2.43(0.21-28.7)$ & 0.54 & & \\
\hline Tumor size $\geq 5 \mathrm{~cm}$ & $2.06(1.29-3.27)$ & $<0.01$ & $2.04(1.31-3.15)$ & $<0.01$ \\
\hline HCC rupture & $6.40(0.55-74.8)$ & 0.14 & & \\
\hline Macrovascular invasion & $2.93(1.00-8.55)$ & 0.05 & $2.99(1.04-8.60)$ & 0.04 \\
\hline
\end{tabular}

OR, odds ratio; $\mathrm{Cl}$, confidence interval; NASH, non-alcoholic steatohepatitis; BMI, body mass index; AFP, alpha-fetoprotein; HCC, hepatocellular carcinoma. 
Table 3. Predictors of neutrophil-lymphocyte ratio $\geq 3.0$ in the entire cohort $(n=789)$

\begin{tabular}{|c|c|c|c|c|}
\hline & Univariat & & Multivari & \\
\hline & OR $(95 \% \mathrm{Cl})$ & $P$-value & OR $(95 \% \mathrm{Cl})$ & $P$-value \\
\hline Age $\geq 65$ years & $1.04(0.72-1.52)$ & 0.82 & $1.18(0.84-1.67)$ & 0.33 \\
\hline Female & $1.26(0.84-1.90)$ & 0.27 & $1.21(0.83-1.78)$ & 0.31 \\
\hline Asian (yes or no) & $0.56(0.36-0.90)$ & 0.01 & $0.62(0.41-0.93)$ & 0.02 \\
\hline Hepatitis B+ & $1.16(0.67-2.00)$ & 0.59 & & \\
\hline Hepatitis C+ & $0.58(0.35-0.95)$ & 0.03 & $0.80(0.55-1.16)$ & 0.25 \\
\hline Alcohol abuse & $0.88(0.58-1.33)$ & 0.54 & & \\
\hline NASH & $1.93(1.04-3.60)$ & 0.04 & $2.34(1.50-3.67)$ & $<0.01$ \\
\hline $\mathrm{BMI} \geq 30 \mathrm{~kg} / \mathrm{m}^{2}$ & $0.80(0.48-1.34)$ & 0.40 & & \\
\hline $\mathrm{BMI} \geq 35 \mathrm{~kg} / \mathrm{m}^{2}$ & $1.05(0.51-2.14)$ & 0.90 & & \\
\hline Smoking (yes or no) & $0.96(0.67-1.39)$ & 0.83 & & \\
\hline Diabetes & $1.27(0.87-1.86)$ & 0.21 & & \\
\hline Hyperlipidemia & $0.99(0.66-1.48)$ & 0.94 & & \\
\hline Hypertension & $0.86(0.59-1.25)$ & 0.44 & & \\
\hline Normal AFP & $0.93(0.66-1.32)$ & 0.69 & & \\
\hline Tumor size $\geq 5 \mathrm{~cm}$ & $2.32(1.67-3.28)$ & $<0.01$ & $2.29(1.64-3.17)$ & $<0.01$ \\
\hline HCC rupture & $6.90(1.84-26.20)$ & $<0.01$ & $5.79(1.83-18.29)$ & $<0.01$ \\
\hline Macrovascular invasion & $2.10(1.20-3.70)$ & $<0.01$ & $2.36(1.37-4.07)$ & $<0.01$ \\
\hline
\end{tabular}

OR, odds ratio; $\mathrm{Cl}$, confidence interval; NASH, non-alcoholic steatohepatitis; BMI, body mass index; AFP, alpha-fetoprotein; HCC, hepatocellular carcinoma.

Table 4. Mean neutrophil-lymphocyte ratio (NLR) by American Joint Committee on Cancer (AJCC) stage and Barcelona Clinic Liver Cancer (BCLC) stage for the entire cohort $(n=789)$

\begin{tabular}{lccl}
\hline Stage & Mean NLR (SD) & Patients (n) & P-value \\
\hline AJCC, stage I & $3.22(2.86)$ & 484 & $<0.01$ \\
\hline AJCC, stage II & $2.94(4.14)$ & 136 & \\
\hline AJCC, stage III & $3.90(3.21)$ & 141 & \\
\hline AJCC, stage IV & $5.72(3.88)$ & 28 & \\
BCLC, stage O & $2.18(1.19)$ & 44 & 0.16 \\
\hline BCLC, stage A1 & $2.68(2.18)$ & 155 & \\
\hline BCLC, stage A2 & $2.62(1.39)$ & 69 & \\
\hline BCLC, stage A3 & $2.95(3.63)$ & 45 & \\
\hline BCLC, stage A4 & $3.21(5.84)$ & 57 & \\
BCLC, stage B & $3.54(2.81)$ & 276 & \\
\hline BCLC, stage C & $4.42(3.43)$ & 81 & \\
BCLC, stage D & $4.39(4.91)$ & 62 & \\
\hline
\end{tabular}

$P$-value represents differences within AJCC or BCLC stage. $\mathrm{SD}$, standard deviation.

(4.23 years). Early recurrence within 1 year occurred in 51 patients (21.7\%). Female gender and NLR $\geq 3$ were associated with more recurrence and patients who had HCC found on surveillance were less likely to recur (Table 5). In the multivariate analysis, HCC found on surveillance was associated with less recurrence while $\mathrm{NLR} \geq 3$ was associated with increased recurrence. For early recurrence, HCC found on surveillance and single tumors were less likely to have early recurrence both with univariate and multivariate analyses (Table 6). NLR $\geq 3$ was associated with increased early recurrence in both univariate and multivariate analyses.

\section{Survival analysis}

In the patients who underwent liver resection, overall mortality at 30 days was $3 \%$. Three patients died from unexpected cardiovascular complications (2 myocardial infarctions and 1 cerebrovascular accident). Two patients died from bleeding complications and one died from liver failure on post-operative day 29. Finally, one patient died from septic complications from an unrelated necrotizing skin infection. No perioperative deaths have occurred in the last 6 years of this study. The 1, 3, and 5-year overall survival was $75.7 \%, 49.8 \%$, and $30.2 \%$ respectively.

NLR $\geq 3$ was associated with poorer overall survival and remained a predictor of survival after adjustment for patient and clinical factors (age, gender, HBV, HCV, cirrhosis, AFP, AST, albu- 
Table 5. Predictors of recurrence of hepatocellular carcinoma (HCC) in patients who underwent liver resection, based on univariate and multivariate analyses $(n=235)$

\begin{tabular}{|c|c|c|c|c|}
\hline & Univari & & Multivar & \\
\hline & OR $(95 \% \mathrm{Cl})$ & $P$-value & OR $(95 \% \mathrm{Cl})$ & $P$-value \\
\hline Age $\geq 65$ years & $0.80(0.40-1.61)$ & 0.54 & $0.78(0.44-1.41)$ & 0.74 \\
\hline Female & $2.10(0.98-4.64)$ & 0.06 & $2.12(1.17-3.94)$ & 0.01 \\
\hline Asian (yes or no) & $0.89(0.32-2.44)$ & 0.82 & & \\
\hline Hepatitis B+ & $1.08(0.30-3.99)$ & 0.90 & & \\
\hline Hepatitis C+ & $0.64(0.20-2.09)$ & 0.46 & & \\
\hline Alcohol abuse & $1.04(0.43-2.53)$ & 0.94 & & \\
\hline $\mathrm{NASH}$ & $0.78(0.20-3.03)$ & 0.72 & & \\
\hline Screened for HCC & $0.35(0.12-1.01)$ & 0.05 & $0.32(0.14-0.75)$ & $<0.01$ \\
\hline $\mathrm{BMI} \geq 30 \mathrm{~kg} / \mathrm{m}^{2}$ & $1.21(0.40-3.68)$ & 0.74 & & \\
\hline $\mathrm{BMI} \geq 35 \mathrm{~kg} / \mathrm{m}^{2}$ & $1.61(0.24-10.6)$ & 0.62 & & \\
\hline Smoking & $0.58(0.29-1.15)$ & 0.12 & & \\
\hline Diabetes & $0.70(0.31-1.52)$ & 0.36 & & \\
\hline Hyperlipidemia & $0.75(0.34-1.64)$ & 0.47 & & \\
\hline Hypertension & $0.97(0.27-3.50)$ & 0.96 & & \\
\hline Normal AFP & $1.10(0.57-2.12)$ & 0.79 & & \\
\hline Single tumor & $0.56(0.23-1.38)$ & 0.21 & & \\
\hline Tumor size $\geq 5 \mathrm{~cm}$ & $1.56(0.77-3.18)$ & 0.22 & & \\
\hline HCC rupture & $1.01(0.33-3.05)$ & 0.99 & & \\
\hline Macrovascular invasion & $0.67(0.09-5.12)$ & 0.70 & & \\
\hline$N L R \geq 1.5$ & $1.02(0.54-6.88)$ & 0.32 & & \\
\hline$N L R \geq 3.0$ & $3.28(1.36-7.93)$ & $<0.01$ & $3.86(1.79-8.29)$ & $<0.01$ \\
\hline
\end{tabular}

OR, odds ratio; Cl, confidence interval; NASH, non-alcoholic steatohepatitis; BMI, body mass index; AFP, alpha-fetoprotein; NLR, neutrophil-lymphocyte ratio.

min, bilirubin and creatinine). NLR $\geq 1.5$ was not associated with survival with or without adjustment of these factors (Fig. 1).

\section{DISCUSSION}

While many studies have demonstrated the prognostic value of NLR in various treatments for HCC, our study is one of few to closely consider other factors that may affect NLR. In examining the entire cohort, NLR appeared to increase with severity of HCC and tumor burden. NLR increased with both AJCC and BCLC stage. Moreover, NLR $\geq 3$ was associated with aggressive tumor behaviors such as large tumor size, tumor rupture, and macrovascular invasion on univariate and multivariate analysis. In particular, tumor rupture was associated with higher NLR with ROC of 0.809 . This was suggested previously by Wang et al. in a metaanalysis examining pretreatment NLR in HCC hepatic resection patients. ${ }^{32}$ They demonstrated higher NLR in patients with vascular invasion and large tumors (greater than $5 \mathrm{~cm}$ ). However, advanced clinical stage was not associated with an elevated NLR. ${ }^{32}$ Our study reinforces the potential prognostic value of an elevated NLR to assess aggressive tumor behavior; and suggest that a continuous numerical variable might be a more useful assessment that may offset the shortcomings of our current staging systems.

Although elevated NLR seems to be associated with severity of disease, other factors such as ethnicity and etiology of chronic liver disease may confound these values. In our cohort, Asian ethnicity and NASH were associated with an elevated NLR in univariate and multivariate analyses. Patients with HCV were more likely to have both $N L R \geq 1.5$ and NLR $\geq 3.0$ in univariate analysis, but this was not demonstrated in multivariate analysis. Diabetes was a predictor of NLR $\geq 1.5$ on univariate and multivariate analysis but not a predictor for NLR $\geq 3$. Age, gender, obesity, smoking, and alcohol use did not affect NLR. Huang et al. previously dem- 
Table 6. Predictors of early recurrence (within 1 year) after liver resection: univariate and multivariate analyses ( $n=235$ )

\begin{tabular}{|c|c|c|c|c|}
\hline & Univaria & & Multivari & \\
\hline & OR $(95 \% \mathrm{CI})$ & $P$-value & OR $(95 \% \mathrm{Cl})$ & $P$-value \\
\hline Age $\geq 65$ years & $0.90(0.37-2.20)$ & 0.86 & $0.84(0.41-1.71)$ & 0.62 \\
\hline Female & $0.87(0.34-2.25)$ & 0.77 & $1.16(0.55-2.60)$ & 0.70 \\
\hline Asian & $0.38(0.11-1.35)$ & 0.14 & & \\
\hline Hepatitis B+ & $1.98(0.37-10.58)$ & 0.43 & & \\
\hline Hepatitis C+ & $1.17(0.25-5.53)$ & 0.85 & & \\
\hline Alcohol abuse & $0.62(0.19-2.00)$ & 0.42 & & \\
\hline NASH & $2.04(0.37-11.18)$ & 0.41 & & \\
\hline Screened for HCC & $0.49(0.12-1.92)$ & 0.11 & $0.34(0.12-0.95)$ & 0.04 \\
\hline $\mathrm{BMI} \geq 30 \mathrm{~kg} / \mathrm{m}^{2}$ & $2.01(0.58-6.96)$ & 0.56 & & \\
\hline $\mathrm{BMI} \geq 35 \mathrm{~kg} / \mathrm{m}^{2}$ & $1.70(0.24-11.91)$ & 0.59 & & \\
\hline Smoking & $0.77(90.32-1.84)$ & 0.55 & & \\
\hline Diabetes & $0.67(0.25-1.85)$ & 0.44 & & \\
\hline Hyperlipidemia & $2.50(0.95-6.56)$ & 0.06 & & \\
\hline Hypertension & $0.74(0.29-1.88)$ & 0.52 & & \\
\hline Normal AFP & $0.78(0.34-1.79)$ & 0.56 & & \\
\hline Single tumor & $0.33(0.12-0.98)$ & 0.05 & $0.41(0.17-0.98)$ & $<0.05$ \\
\hline Tumor size $\geq 5 \mathrm{~cm}$ & $1.53(0.62-3.80)$ & 0.36 & & \\
\hline HCC rupture & $2.11(0.61-7.37)$ & 0.24 & & \\
\hline Macrovascular invasion & $1.87(0.21-16.49)$ & 0.58 & & \\
\hline$N L R \geq 1.5$ & $0.81(0.17-3.85)$ & 0.79 & & \\
\hline$N L R \geq 3.0$ & $3.45(1.08-11.02)$ & 0.04 & $4.33(1.71-10.96)$ & $<0.01$ \\
\hline
\end{tabular}

$\mathrm{OR}$, odds ratio; $\mathrm{Cl}$, confidence interval; NASH, non-alcoholic steatohepatitis; $\mathrm{HCC}$, hepatocellular carcinoma; BMI, body mass index; AFP, alpha-fetoprotein; NLR, neutrophil-lymphocyte ratio.

onstrated a significant difference in distribution of NLR by underlying chronic liver disease. ${ }^{33}$ However, in their cohort of 1,659 patients, only 502 patients had a reported etiology for chronic liver disease; and $68 \%$ had HBV, $0.6 \%$ had HCV, and $16 \%$ were coinfected with HBV and HCV. Wang et al. also reported that HBV was associated with an elevated NLR in their meta-analysis of 17 studies of HCC patients who underwent liver resection. ${ }^{32}$ However, 16 of these studies were done in Asian countries and only 3 of the studies had information on HBV. Many previous studies that conducted these etiologic analyses have originated in China or countries with a very high prevalence of HBV. ${ }^{24,29,34-44}$ In this study, more heterogeneous population with greater representation of $\mathrm{HCV}$ and NASH as an underlying chronic liver disease may allow for a more accurate comparison of these risk factors and how they may influence NLR.

In our subgroup of patients who underwent hepatic resection,
NLR had prognostic value on outcome. NLR $\geq 3$ was predictive of recurrence and early recurrence in both univariate and multivariate analysis. Additionally, NLR $\geq 3$ was associated with decreased overall survival. Even after adjustment for multiple variables, NLR $\geq 3$ was still predictive of poor survival. Previous studies examined similar outcomes with elevated preoperative NLR exhibiting decreased overall and disease-free survival. ${ }^{21,32}$ Our study corroborates these studies of preoperative NLR demonstrating the potential to identify a subset of resectable HCC patients that may benefit from adjuvant treatment or closer surveillance.

The precise mechanism by which an elevated preoperative NLR confers worse survival cannot be clearly elucidated from retrospective studies such as ours, but several hypotheses exist. The tumor microenvironment can potentially regulate hepatocellular carcinogenesis. ${ }^{45}$ Infiltration of peritumoral neutrophils and interleukin-17 (IL-17) producing cells has been reported to increase an- 

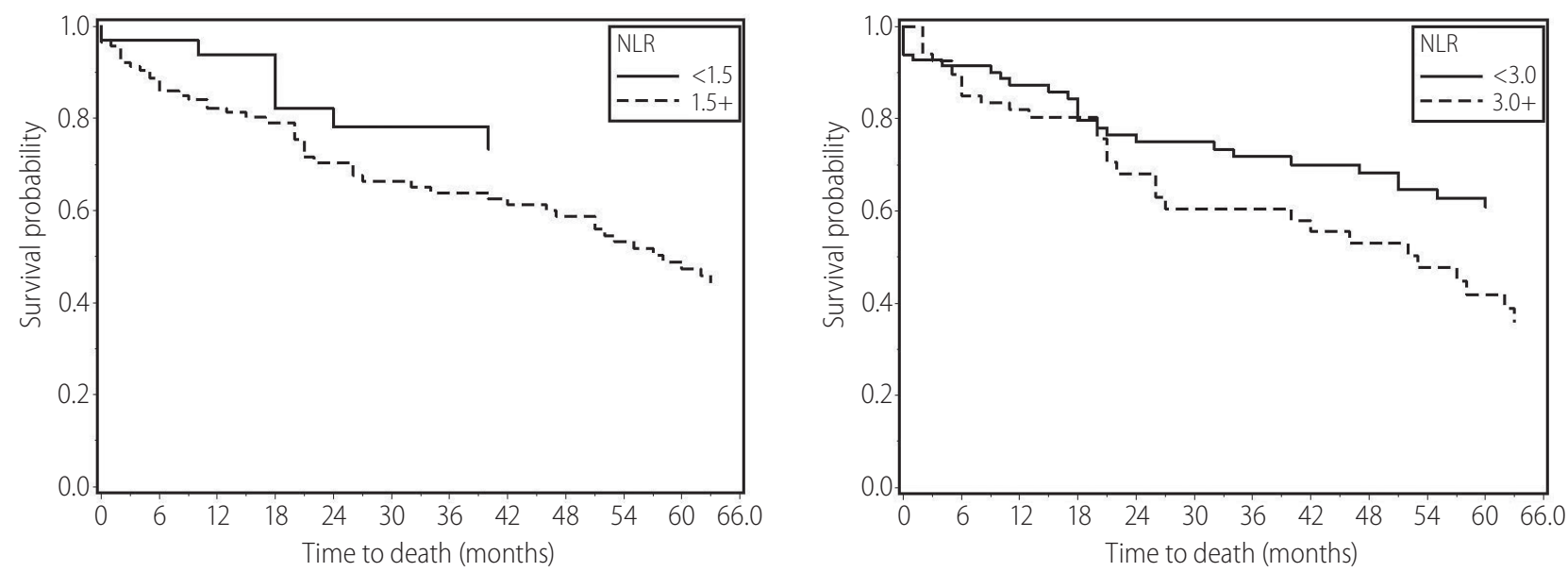

\begin{tabular}{lccccl}
\hline Patients & Measure & P-value & Hazard ratio & 95\% confidence interval & \multicolumn{1}{c}{ Covariates } \\
\hline 143 & $\mathrm{NLR} \geq 1.5$ & 0.11 & 1.66 & $0.89-3.10$ & Unadjusted \\
\hline 113 & $\mathrm{NLR} \geq 1.5$ & 0.60 & 1.23 & $0.57-2.66$ & $\begin{array}{c}\text { Age, sex, HBV, HCV, cirrhosis, AFP, AST, albumin, } \\
\text { bilirubin, creatinine }\end{array}$ \\
\hline 143 & $\mathrm{NLR} \geq 3.0$ & 0.01 & 1.83 & $1.13-2.95$ & Unadjusted \\
113 & $\mathrm{NLR} \geq 3.0$ & 0.02 & 2.04 & $1.13-3.69$ & $\begin{array}{c}\text { Age, sex, HBV, HCV, cirrhosis, AFP, AST, albumin, } \\
\text { bilirubin, creatinine }\end{array}$ \\
\hline
\end{tabular}

Figure 1. Kaplan Meier curves comparing survival with neutrophil-lymphocyte ratio (NLR) $\geq 1.5$ and NLR $\geq 3$ for resected patients before and after adjustment for age, sex, hepatitis B virus (HBV), hepatitis C virus (HCV), cirrhosis, alpha-fetoprotein (AFP), aspartate aminotransferase (AST), albumin, bilirubin, and creatinine.

giogenesis and, thereby, promote tumor growth to ultimately confer worse survival in patients with HCC. ${ }^{46-48}$ Infiltrating lymphocytes are typically CD4+ T-helper or T-reg cells. ${ }^{45} \mathrm{~T}$-reg cells promote immune tolerance to neoplastic cells, and a balance toward T-reg over CD8+ cells is associated with a worse prognosis. ${ }^{49}$ However, an upregulation of CD4+ T helper cells may drive the host immune system toward an antitumor reaction. Taken together, the relative neutrophilia and lymphopenia (predominantly in CD4+ and CD8+ cells) in the tumor microenvironment may promote tumorigenesis and a systemic NLR in the peripheral blood may be an apt systemic surrogate for the tumor inflammatory and immune locale.

This study had limitation from a single-center study and the data to calculate NLR was collected retrospectively. While we chose to report values of neutrophils and lymphocytes within two weeks of the initial visit to the surgeons, some of these values may have been obtained while the patient was hospitalized. Intervening factors such as infection, bleeding, or other acute illness that may be associated with an inflammatory state may have affected these values. Furthermore, while we had information on viral hepatitis serologies, we did not have more detailed informa- tion on viral load or use of antiviral agents. Finally, blood was obtained in multiple different inpatient or outpatient laboratories and we cannot account for slight variations between the laboratories.

Despite these limitations, this study involves use of a carefully annotated, prospectively collected database which provided robust information on risk factors, viral hepatitis, and tumor characteristics. We also have reliable information on various treatments and survival. NLR has previously been shown to be a prognostic factor in recurrence and survival in large studies of patients who underwent liver resection, transplantation, and various locoregional therapies. However, most of these studies do not account for factors that may affect NLR, including demographics, ethnicity, and etiology of chronic liver disease in a heterogeneous population. Our study showed that Asian race, HCV, NASH, and diabetes mellitus affect NLR and more importantly, NLR may be a prognostic marker for disease severity with increased values in those patients with large tumors, vascular invasion, and tumor rupture. Intervening factors may render NLR difficult to interpret, and cut-off values may be difficult to establish. More detailed studies will be needed to determine the optimal use of NLR as a 
prognostic biomarker in HCC.

\section{Authors' contribution}

Linda Wong: Data collection, analysis, and drafting of manuscript.

Kliment Bozhilov: Concept, design, and drafting of manuscript. Brenda Hernandez: Data analysis.

Sandi Kwee: Concept, design, and data analysis.

Owen Chan: Critical review and revision.

Luke Ellis: Data collection.

Loic LeMarchand: Critical review and revision.

\section{Funding suport}

This study was partially supported by NIH grant 2P30 CA071789-13.

\section{Conflicts of Interest}

Dr. Linda Wong is on the Speakers Bureau for Eisai and Bayer Healthcare. The other authors have no conflicts of interest to declare.

\section{REFERENCES}

1. Stewart BW, Wild CP. World cancer Report 2014. World Health Organization, International Agency for Research on Cancer web site, $<$ http://publications.iarc.fr/Non-Series-Publications/World-CancerReports/World-Cancer-Report-2014>. Accessed 1 Jan 2019.

2. Choo SP, Tan WL, Goh BKP, Tai WM, Zhu AX. Comparison of hepatocellular carcinoma in Eastern versus Western populations. Cancer 2016;122:3430-3436.

3. El-Serag HB. Hepatocellular carcinoma. N Engl J Med 2011;365:11181127.

4. Petrick JL, Kelly SP, Altekruse SF, McGlynn KA, Rosenberg PS. Future of hepatocellular carcinoma incidence in the United States forecast through 2030. J Clin Oncol 2016;34:1787-1794.

5. El-Serag HB, Kanwal F. Epidemiology of hepatocellular carcinoma in the United States: where are we? Where do we go? Hepatology 2014;60:1767-1775.

6. Heimbach JK, Kulik LM, Finn RS, Sirlin CB, Abecassis MM, Roberts $L R$, et al. AASLD guidelines for the treatment of hepatocellular carcinoma. Hepatology 2018;67;358-380.

7. European Association for the Study of the Liver; European Organisation for Research and Treatment of Cancer. EASL-EORTC clinical practice guidelines: management of hepatocellular carcinoma. J Hepatol 2012;56:908-943.
8. Pompili M, Saviano A, de Matthaeis N, Cucchetti A, Ardito F, Federico $B$, et al. Long-term effectiveness of resection and radiofrequency ablation for single hepatocellular carcinoma $\leq 3 \mathrm{~cm}$. Results of a multicenter Italian survey. J Hepatol 2013;59:89-97.

9. Tralhão JG, Dagher I, Lino T, Roudié J, Franco D. Treatment of tumour recurrence after resection of hepatocellular carcinoma. Analysis of 97 consecutive patients. Eur J Surg Oncol 2007;33:746-751.

10. Shimada K, Sano T, Sakamoto $Y$, Kosuge T. A long-term followup and management study of hepatocellular carcinoma patients surviving for 10 years or longer after curative hepatectomy. Cancer 2005;104:1939-1947.

11. Mazzaferro V, Bhoori S, Sposito C, Bongini M, Langer M, Miceli R, et al. Milan criteria in liver transplantation for hepatocellular carcinoma: an evidence-based analysis of 15 years of experience. Liver Transpl 2011;17(Suppl 2):S44-S57.

12. Roayaie S, Schwartz JD, Sung MW, Emre SH, Miller CM, Gondolesi $\mathrm{GE}$, et al. Recurrence of hepatocellular carcinoma after liver transplant: patterns and prognosis. Liver Transpl 2004;10:534-540.

13. Onaca N, Davis GL, Goldstein RM, Jennings LW, Klintmalm GB. EXpanded criteria for liver transplantation in patients with hepatocellular carcinoma: a report from the International Registry of Hepatic Tumors in Liver Transplantation. Liver Transpl 2007;13:391-399.

14. Vibert E, Azoulay D, Hoti E, lacopinelli S, Samuel D, Salloum C, et al. Progression of alphafetoprotein before liver transplantation for hepatocellular carcinoma in cirrhotic patients: a critical factor. Am J Transplant 2010;10:127-137.

15. Vora SR, Zheng H, Stadler ZK, Fuchs CS, Zhu AX. Serum alphafetoprotein response as a surrogate for clinical outcome in patients receiving systemic therapy for advanced hepatocellular carcinoma. Oncologist 2009;14:717-725.

16. Coussens LM, Werb Z. Inflammation and cancer. Nature 2002;420:860867.

17. Chew V, Tow C, Teo M, Wong HL, Chan J, Gehring A, et al. Inflammatory tumour microenvironment is associated with superior survival in hepatocellular carcinoma patients. J Hepatol 2010;52:370379.

18. Gao Q, Qiu SJ, Fan J, Zhou J, Wang XY, Xiao YS, et al. Intratumoural balance of regulatory and cytotoxic $T$ cells is associated with prognosis of hepatocellular carcinoma after resection. J Clin Oncol 2007; 25:2586-2593.

19. Wada Y, Nakashima O, Kutami R, Yamamoto O, Kojiro M. Clinicopathological study on hepatocellular carcinoma with lymphocytic infiltration. Hepatology 1998;27:407-414.

20. Qin LX. Inflammatory immune responses in tumor microenvironment and metastasis of hepatocellular carcinoma. Cancer Microenviron 2012;5:203-209.

21. Najjar M, Agrawal S, Emond JC, Halazun KJ. Pretreatment neutrophil-lymphocyte ratio: useful prognostic biomarker in hepatocellular 
Linda Wong, et al.

Elevated neutrophil-to-lymphocyte ratio in liver cancer

carcinoma. J Hepatocell Carcinoma 2018;5:17-28.

22. Cao $Y$, Jiang Z, Wang S, Zhang H, Jiang Y, Lv L. Prediction of longterm survival rates in patients undergoing curative resection for solitary hepatocellular carcinoma. Oncol Lett 2018;15:2574-2582.

23. Chan AW, Chan SL, Wong GL, Wong VW, Chong CC, Lai PB, et al. Prognostic Nutritional Index (PNI) predicts tumor recurrence of very early/early stage hepatocellular carcinoma after surgical resection. Ann Surg Oncol 2015;22:4138-4148.

24. Fu SJ, Shen SL, Li SQ, Hua YP, Hu WJ, Liang LJ, et al. Prognostic value of preoperative peripheral neutrophil-to-lymphocyte ratio in patients with $\mathrm{HBV}$-associated hepatocellular carcinoma after radical hepatectomy. Med Oncol 2013;30:721.

25. Hung HC, Lee JC, Cheng CH, Wu TH, Wang YC, Lee CF, et al. Impact of neutrophil to lymphocyte ratio on survival for hepatocellular carcinoma after curative resection. J Hepatobiliary Pancreat Sci 2017;24:559-569.

26. Pang S, Zhou Z, Yu X, Wei S, Chen Q, Nie S, et al. The predictive value of integrated inflammation scores in the survival of patients with resected hepatocellular carcinoma: a retrospective cohort study. Int J Surg 2017;42:170-177.

27. Ren $Z$, He $S$, Fan $X$, He F, Sang $W$, Bao $Y$, et al. Survival prediction model for postoperative hepatocellular carcinoma patients. Medicine (Baltimore) 2017;96:e7902.

28. Shimoda M, Tago K, Shiraki T, Mori S, Kato M, Aoki T, et al. Risk factors for early recurrence of single lesion hepatocellular carcinoma after curative resection. World J Surg 2016;40:2466-2471.

29. Yang HJ, Guo Z, Yang YT, Jiang JH, Qi YP, Li JJ, et al. Blood neutrophil-lymphocyte ratio predicts survival after hepatectomy for hepatocellular carcinoma: a propensity score-based analysis. World J Gastroenterol 2016;22:5088-5095.

30. Yu Y, Song J, Zhang R, Liu Z, Li Q, Shi Y, et al. Preoperative neutrophil-to-lymphocyte ratio and tumor-related factors to predict microvascular invasion in patients with hepatocellular carcinoma. Oncotarget 2017:8:79722-79730.

31. Zheng J, Seier K, Gonen M, Balachandran VP, Kingham TP, D'Angelica $\mathrm{Ml}$, et al. Utility of serum inflammatory markers for predicting microvascular invasion and survival for patients with hepatocellular carcinoma. Ann Surg Oncol 2017;24:3706-3714.

32. Wang Y, Peng C, Cheng Z, Wang X, Wu L, Li J, et al. The prognostic significance of preoperative neutrophil-lymphocyte ratio in patients with hepatocellular carcinoma receiving hepatectomy: a systemic review and meta-analysis. Int J Surg 2018;55:73-80.

33. Huang $G Q$, Zhu GQ, Liu YL, Wang LR, Braddock M, Zheng MH, et al. Stratified neutrophil-to-lymphocyte ratio accurately predict mortality risk in hepatocellular carcinoma patients following curative liver resection. Oncotarget 2016;7:5429-5439.

34. Guo, ZX, Wei W, Zhong C, Shi M, Chen MS, Guo RP. Correlation of preoperative neutrophil-to-lymphocyte ratio to prognosis of young patients with hepatocellular carcinoma. Ai Zheng 2009;28:12031208.

35. Lu SD, Wang YY, Peng NF, Peng YC, Zhong JH, Qin HG, et al. Preoperative ratio of neutrophils to lymphocytes predicts postresection survival in selected patients with early or intermediate stage hepatocellular carcinoma. Medicine (Baltimore) 2016;95:e2722.

36. Liu Y, Wang ZX, Cao Y, Zhang G, Chen WB, Jiang CP. Preoperative inflammation-based markers predict early and late recurrence of hepatocellular carcinoma after curative hepatectomy. Hepatobiliary Pancreat Dis Int 2016;15:266-274.

37. Goh BK, Kam JH, Lee SY, Chang CY, Allen JC, Jeyaraj P, et al. Significance of neutrophil-to-lymphocyte ratio, platelet-to-lymphocyte ratio and prognostic nutrition index as preoperative predictors of early mortality after liver resection for huge $(\geq 10 \mathrm{~cm})$ hepatocellular carcinoma. J Surg Oncol 2016;113:621-627.

38. Okamura Y, Ashida R, Ito T, Sugiura T, Mori K, Uesaka K. Preoperative neutrophil to lymphocyte ratio and prognostic nutritional index predict overall survival after hepatectomy for hepatocellular carcinoma. World J Surg 2015;39:1501-1509.

39. Okamura Y, Sugiura T, Ito T, Yamamoto Y, Ashida R, Mori K, et al. Neutrophil to lymphocyte ratio as an indicator of the malignant behaviour of hepatocellular carcinoma. Br J Surg 2016;103:891-898.

40. Peng W, Li C, Wen TF, Yan LN, Li B, Wang WT, et al. Neutrophil to lymphocyte ratio changes predict small hepatocellular carcinoma survival. J Surg Res 2014;192:402-408.

41. Liao W, Zhang J, Zhu Q, Qin L, Yao W, Lei B, et al. Preoperative neutrophil-to-lymphocyte ratio as a new prognostic marker in hepatocellular carcinoma after curative resection. Transl Oncol 2014;7:248255.

42. Mano Y, Shirabe K, Yamashita Y, Harimoto N, Tsujita E, Takeishi K, et al. Preoperative neutrophil-to-lymphocyte ratio is a predictor of survival after hepatectomy for hepatocellular carcinoma: a retrospective analysis. Ann Surg 2013;258:301-305.

43. Wang Q, Blank S, Fiel MI, Kadri H, Luan W, Warren L, et al. The severity of liver fibrosis influences the prognostic value of inflammation-based scores in hepatitis B-associated hepatocellular carcinoma. Ann Surg Oncol 2015;22 Suppl 3:S1125-S1132.

44. Li C, Wen TF, Yan LN, Li B, Wang WT, Yang JY, et al. Postoperative neutrophil-to-lymphocyte ratio plus platelet-to-lymphocyte ratio predicts the outcomes of hepatocellular carcinoma. J Surg Res 2015;198:73-79.

45. Hernandez-Gea V, Toffanin S, Friedman SL, Llovet JM. Role of the microenvironment in the pathogenesis and treatment of hepatocellular carcinoma. Gastroenterology 2013;144:512-527.

46. Kuang DM, Zhao Q, Wu Y, Peng C, Wang J, Xu Z, et al. Peritumoral neutrophils link inflammatory response to disease progression by fostering angiogenesis in hepatocellular carcinoma. J Hepatol 2011;54:948-955. 
47. Zhang JP, Yan J, Xu J, Pang XH, Chen MS, Li L, et al. Increased intratumoral IL-17-producing cells correlate with poor survival in hepatocellular carcinoma patients. J Hepatol 2009;50:980-989.

48. Zhou SL, Zhou ZJ, Hu ZQ, Huang XW, Wang Z, Chen EB, et al. Tumor-associated neutrophils recruit macrophages and T-regulatory cells to promote progression of hepatocellular carcinoma and resis- tance to sorafenib. Gastroenterology 2016;150:1646-1658.e17.

49. Fu J, Xu D, Liu Z, Shi M, Zhao P, Fu B, et al. Increased regulatory $T$ cells correlate with CD8 T-cell impairment and poor survival in hepatocellular carcinoma patients. Gastroenterology 2007;132:23282339. 